\title{
The evolution of energy requirements of smartphones based on user behaviour and implications of the COVID-19 era
}

\author{
Abdullah Mahmoud Almasri ${ }^{1}$, Luis Borges Gouveia ${ }^{2}$ \\ ${ }^{1}$ College of Computer and Info Science, Prince Sultan University, Saudi Arabia \\ ${ }^{2}$ Science and Technology Faculty, University Fernando Pessoa, Portugal
}

\section{Article Info \\ Article history: \\ Received Aug 26, 2020 \\ Revised Oct 19, 2020 \\ Accepted Nov 11, 2020}

\section{Keywords:}

Applications

COVID-19

Energy

Smartphones

\begin{abstract}
Smartphones have evolved to become frequent companions to humans. The common problem shared by Android users of smartphones was, and continues to be, about saving their batteries and preventing the need to use any recharging tools. A significant number of studies have been performed in the general field of "saving energy in smartphones". During a state of global lockdown, the use of smartphone devices has skyrocketed, and many governments have implemented location-tracking applications for their citizens as means of ensuring that the imposed governmental restrictions are being adhered to. Since smartphones are battery-powered, the opportunity to conserve electricity and ensure that the handset does not have to be charged so much or that it does not die and impede location-tracking during this period of crisis is of vital significance, impacting not only the reliability of tracking, but also the usability of the mobile itself. While there are methods to reduce the battery's drain from mobile app use, they are not fully utilized by users. Simultaneously, the following the manuscript demonstrates the growing prevalence of mobile applications in daily lives, as well as the disproportionally increasing phone functionality, which results in the creation of a dependency towards smartphone use and the need of energy to recharge and operate theses smartphones.
\end{abstract}

This is an open access article under the CC BY-SA license.

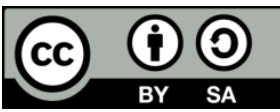

\section{Corresponding Author:}

Abdullah Mahmoud Almasri

College of Computer and Information Sciences

Prince Sultan University

Riyadh, Saudi Arabia

Email: aalmasri@psu.edu.sa

\section{INTRODUCTION}

The amount of computations and services in smartphones increases exponentially over the last couple of years, following a style of growth that correlates with Moore's Law. Specifically, growth is observed in areas such as codecs design, video compression, efficient screen display, yet in terms of the smartphone battery the depletion problem remains. This issue is considered the biggest hinderance of electronic devices in general and smartphone devices in particular [1]. It is considered that this issue will continue becoming more and more relevant as mobile devices (e.g. smartphones and tablets) continue growing in popularity amongst users worldwide. Some studies also demonstrate a trend, where users begin accessing the web solely or mainly through a smartphone device [2] or using smartphones as their main device. Thus, the need to improve battery life is present. The issue is observed by a variety of scholars, some illustrating the lagging development in the area of battery performance when compared to device functionality or hardware characteristics. 
A study done by Panasonic (one of the leading battery manufacturers in the world) estimates the annual improvement in the life of their batteries to be just $11 \%$. The slow progress is a result of the lack of or slow introduction of new technologies in the field of battery technologies. Android phones in particular can benefit from an improved battery capacity due to the potentially limitless functionality that the operation system provides to its users with regards to applications, design and other customisable features [3]. In addition, a dedicated power management API is written in applications framework layer, which mandates that Android apps request CPU resources with wake locks through the application framework and native Linux libraries as depicted in Figure 1. In addition, power on Android devices can also be controlled through context aware power management, which is typically done through power saving applications. User behaviour can also be used for control of the battery's drainage and its efficiency, as will be explored in upcoming sections. While these techniques and tools exist, their use is not always efficient, nor does it detract from the primary issue at hand, which is that the speed of development of smartphone computational requirements and services does not correlate with battery performance.

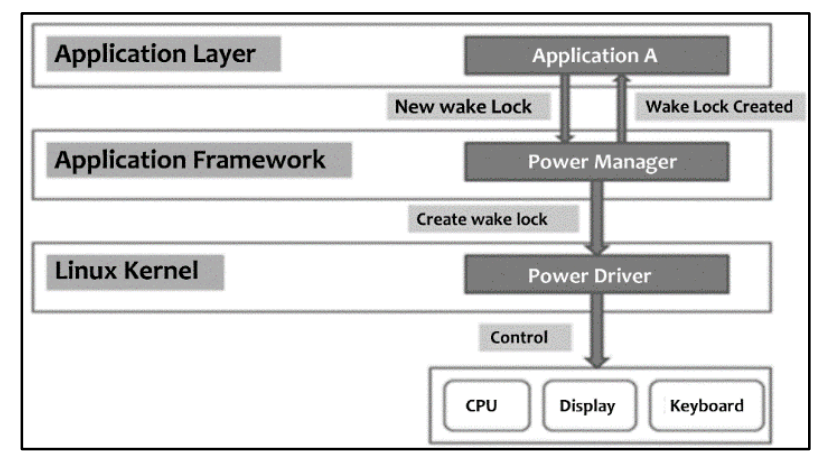

Figure 1. Android power management architecture

\section{CONTINUOUS RECHARGING VS SAVING}

Academic research in this field indicates that consumers have poor knowledge of the characteristics of mobile power, and are therefore ignorant of the power-saving settings available to them as owners of such devices $[4,5]$. Although battery life is perceived to be significant for a large group of mobile users, the analysis indicates that current battery interfaces offer limited knowledge as a result of which users create inaccurate mental models of how the battery is discharged and how the remaining percentage of the battery is correlated with the use of applications. [6]. In addition, consumers do not understand how to charge their batteries in order to support their intended use of the units. As a result, a variety of behaviours in relation to battery saving are observed, many of which are inefficient in relation to the lifetime of the battery or the device. For instance, many users hinder the utility of their devices through erratic usage behaviour, with data demonstrating that a single user can drain $298 \%$ of the battery's capacity one day (charging 3 times) and discharging only $38 \%$ on another day [7].

Another behaviour is not draining the battery fully, before charging it, as observed in Wagner et al. study. Battery exhaustion (emptying the battery) is considered a failure of the user to manage battery consumption, yet it occurs at least every 11 days for $50 \%$ of smartphone users in Wagner et al. sample group. While full battery depletion is not recommended on a regular basis by battery suppliers, it is found that consumers primarily avoid lower levels of batteries, with a daily average of 30 per cent of the lowest percentage of batteries. being $30 \%$. Android smartphones only issue a notification to charge the phone by the time it reaches 15\%; however, research demonstrates users charge the device before this critical level (as deemed by the manufacturers) is reached. Despite the small variance of the battery levels of users worldwide that researchers observe, the variance on charging patterns is great. Some users tend to charge for a limited amount of time during the day, while others allow for a full discharge, followed by a longer charge duration. This can lead to the conclusion that charging behaviour is systematic and simultaneous erratic at times, and users typically interrupt their phones' charging cycle thus reducing battery life. The listed behaviours are linked with a variety of disadvantages. For instance, the charging duration (which is considered the amount of time the user keeps their phone connected unnecessarily) is considered an issue in two ways. Firstly, charging for a long period of time would have damaged the battery due to overheating and overvoltage [8], although it is actually considered a matter of energy consumption. While, as previously discussed, the smartphones alert the user when they need to be charged, they do not alert them when they have finished 
charging, which is considered by scholars another hinderance of current models at work. Thus, a need for involved automated power features to assist with power management is required, as studies show only $80 \%$ of users take any measures related to the increased battery lifetime of their devices.

\section{GREEN COMPUTING AS A BASIC APPROACH}

Green computing refers to the practice and techniques of using computing energy in an environmentally sustainable manner while at the same time ensuring maximum overall computing efficiency. It is also defined as' the study and practice of environmentally sustainable computing or IT' [9]. It is projected that, last year, \$22 million is wasted on energy utility costs by mobile users as a result of having their cell phones plugged in for more time than is necessary to sustain a maximum charge. This has resulted in two goals. Firstly, to improve the energy efficiency of mobile devices as means of achieving the goal of green computing and enable energy savings [10]. Secondly, to reduce the consumption of energy required by smartphone devices through not only (as in the past) focus on optimising software and run time, but also through improving the battery's run time through development of battery saving software applications [11]. Mobile cloud computing is the emergence of multiple internet-based technologies, through which mobile users can acquire benefits of cloud computing and achieve green computing by using their mobile device [12, 13]. However, as D'Ambrosio et al. argued, the energy use of web surfing practices is not well discussed in scholarly literature as a result of a lack of study of users' actual surfing sessions, which reveal that over 63\% of users are already using their mobile devices to go online. Arguably, a gap exists in better understanding mobile web browsing behaviour, which is unanimously considered by scholars a potential way of enabling green computing. Nonetheless, efforts in the area are being made by researchers. For instance, Gai et al. [14] suggest a cloud computing model for green computing, which is dynamic, energy-aware, cloudlet-based, and aimed at mobile optimisation. Specifically, it aims to solve the supplementary energy consumptions during the wireless communications through utilisation of dynamic cloudlets (DCL). Couto et al. propose a technique and a tool for detection of anomalous energy consumption in applications for Android smartphones, subsequently relating it directly with the source code of the application. Specifically, their paper presents a dynamically adjusted model for energy expenditure for the Android ecosystem, which is supported in a variety of devices [15].

\section{SMARTPHONE BATTERY-SAVING AS A GLOBAL NEED}

Considering the mentioned issues in relation to unsustainable charging behaviors, the issue of battery saving for smartphones can be perceived as a global issue. This is also in the light of the results that demonstrate that the number of mobile users worldwide is growing last year as shown in Figure 2. Research demonstrates that none of the currently used techniques for battery and power management efficiently contribute to the green computing concept as none take into account the access to technology used, individual user behavior, and user preferences [16]. The urgent need for more efficient methods of conserving battery and improving its performance for Android smartphones is, thus, a global ecological concern [17]. Not only does this boost the overall consumer experience, minimize energy loss, but also minimize the physical waste of failed batteries, which are not ideal for recycling, since the battery can be charged a range of times before it collapses.

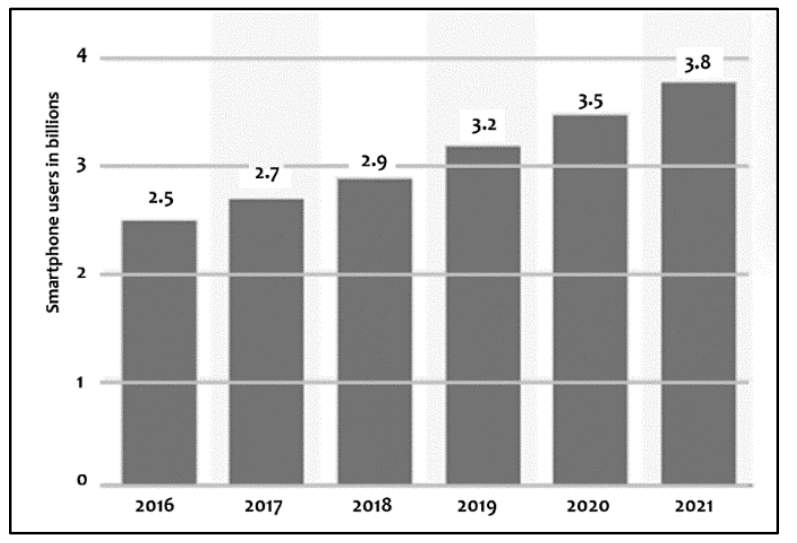

Figure 2. Number of smartphone users worldwide (in billions) 


\section{THE CONVERSION FROM MOBILE PHONES TO SMARTPHONES}

Many scholars believe the most influential years for the development of the smartphone happened between 2007 and 2011, which is when the smartphone surpassed traditional mobile phones in sales and revenue [18] as shown in Figure 3. Specifically, this shift happened throughout this period sequentially in various parts of the world, such as in 2010 in the UK and Spain, early 2011 in Germany and France and later that year in Italy and Canada and the US.

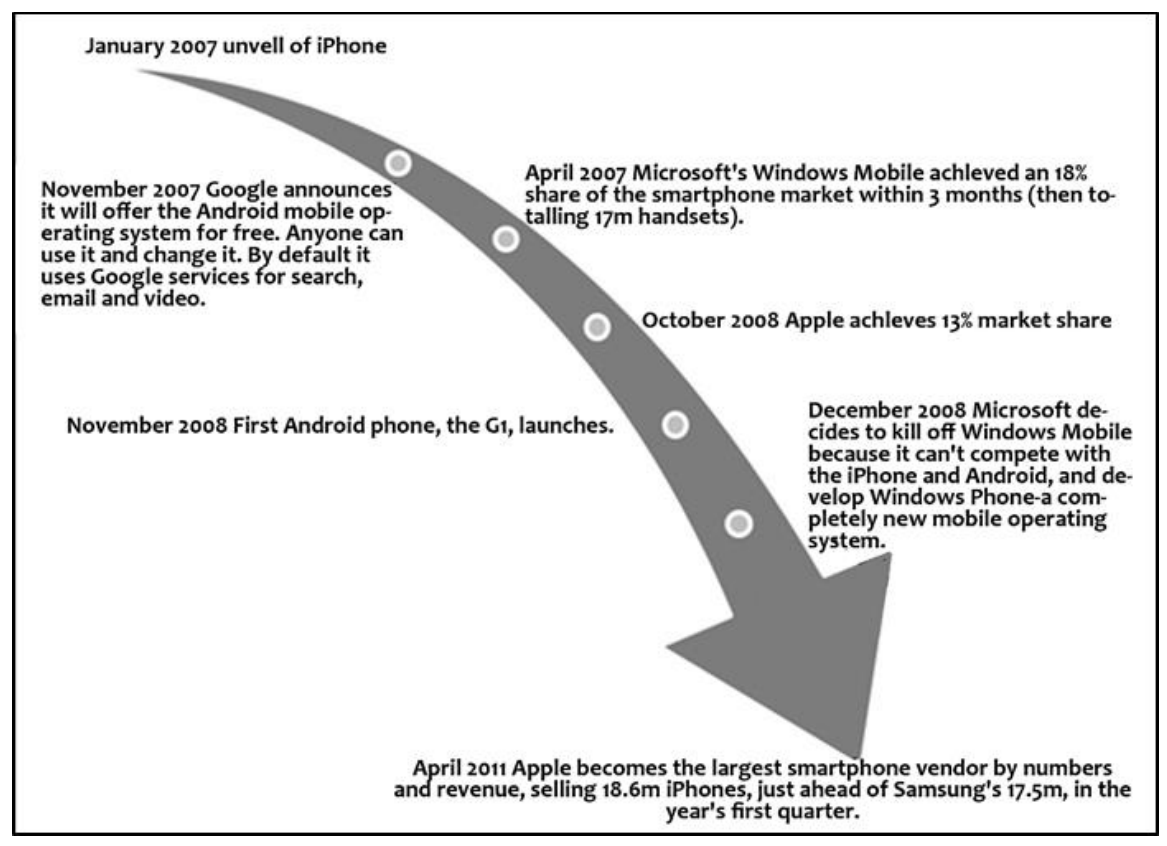

Figure 3. Conversion of world usage from mobile to smartphones (key events) (2007-2011)

Android phones in particular have experienced a significant development in the past 10 years. In terms of its performance characteristics, researchers believe the operating system outperforms iOS as Android relies on a more robust hardware and software architecture as shown in Figure 4. The performance jump can be correlated with the introduction of big.LITTLE octa-core SoCs in Android smartphones, as well a significant improvement of battery life in less demanding tasks. The Figure 5 demonstrates that the industry average with regards to battery life of Android devices has improved in the period between 2013-2016. In addition, data demonstrates that for the same period the recharging time has rapidly decreased from 140 minutes in 2013 (reaching 170 minutes in 2014) to 100 minutes in 2016 [19].

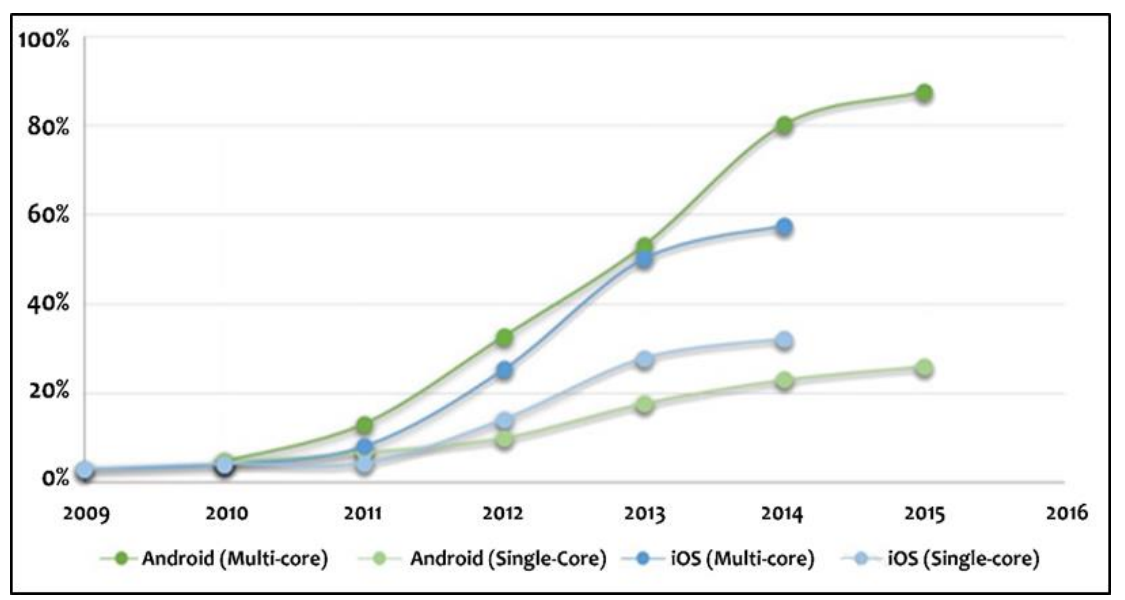

Figure 4. Android vs iOS global smartphone market share by performance 


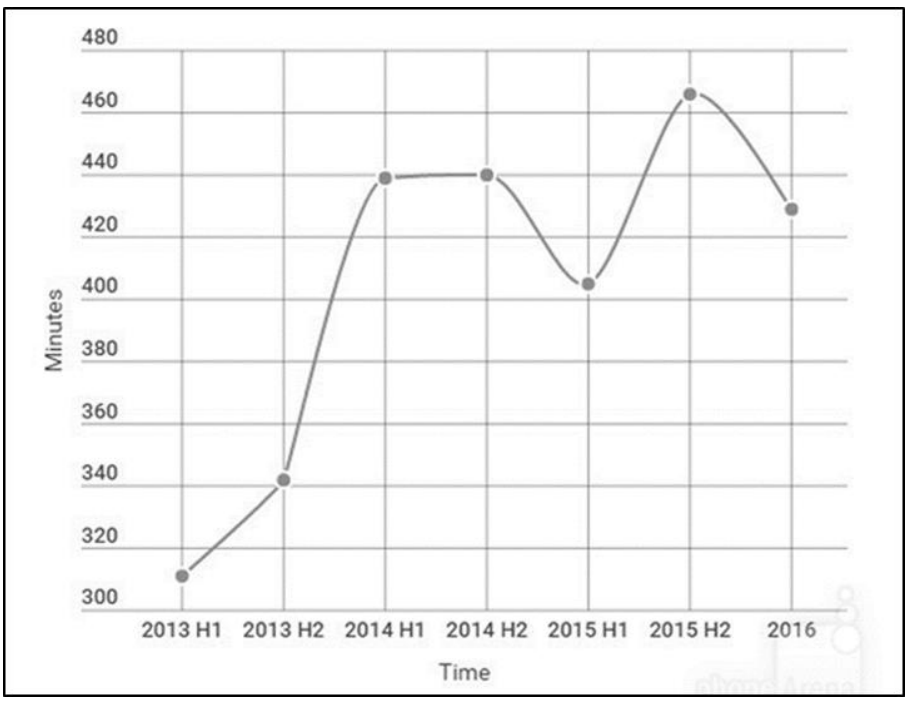

Figure 5. Battery life industry average

\section{TECHNOLOGY VS ENERGY CURVE}

It can be argued based on the made thus far arguments that there is an observed reverse relationship of the available technological capacity of smartphone devices and their battery life. This is signified graphically below, demonstrating that current smartphones, while providing a variety of capabilities to the user, limit their availability of taking advantage of them through a comparatively smaller battery life than previously, in times where phones had a considerably smaller amount of functionalities or otherwise performance capabilities. In addition, this can be a result of the increased digital dependency that the improved device functionality enables, which promotes the usage of the phones for a larger proportion of the day from consumers across all ages [20-22].

\section{REVOLUTION OF SMARTPHONES USAGE HABITS}

There has also been an observed shift in smartphone usage habits for users across all ages. While previously, mobile devices were used primarily for communication purposes, today smartphones are used for a variety of reasons varying from entertainment to child emotion control. For instance, several studies have demonstrated that smartphones are used extensively by parents as an aid for controlling their children's emotions, creating a digital dependency from an early age [23]. In teenage years, the devices can provide as sense of independence to their users, and are currently used for creation of digital socio-cultural values and religious beliefs and practices, which are shared amongst teens across the world through the medium of the smartphone device. Millennial and young adults use their devices for entertainment purposes [24], while the older generation is currently following a trend of discovering online social networks through their smartphones [25]. Smartphones are also becoming more common in developing nations, with a variety of technologically-focused organizations introducing services tailored to the needs of individuals in those regions [26].

\section{SMARTPHONES APPS UBIQUITY IN THE LIFE ROUTINES}

According to industry analysts, there are three phases of app development, illustrated in the Figure 6. Scholars believe that the development of the Android OS has significantly promoted the development of a variety of applications, increasing both the demand and supply for such applications [27]. The development of the OS has seen rapid change in a variety of features offered, which have made a measurable impact on mobile app development. Due to the rapid growth of smartphone apps for a variety of reason and the shown previously duration of product competition for user attention, product developers have devised ways to attract and hold user attention. One such approach is gamification of the app [28], while other apps, such as those in the social media category implement psychological gratification mechanisms to sustain the attention of the users. As a result, smartphone apps have become intricately integrated with life routines. For instance, Wang et al. [29] study demonstrates that smartphone apps are integrated in every aspect of travel from the booking of the travel medium, to the check in process at the airport or at the hotel, through the navigation at the destination and sharing of memories in a digital format (e.g. through protos or 
status updates) and so on. Smartphone apps are now becoming increasingly popular in wellness care and weight management, as well as exercise and bodybuilding workouts [30-32]. One of the most important ways in which mobile apps are intertwined with everyday activities and habits is that of socialization. Ongoing debates fail to resolve the question whether the presence of such a variety of social media apps in daily lives is positive or toxic, with some arguing it reduces social isolation [33, 34], and others claiming it leads to reduces overall well-being quoting the rise in depression and mental health disease [35].

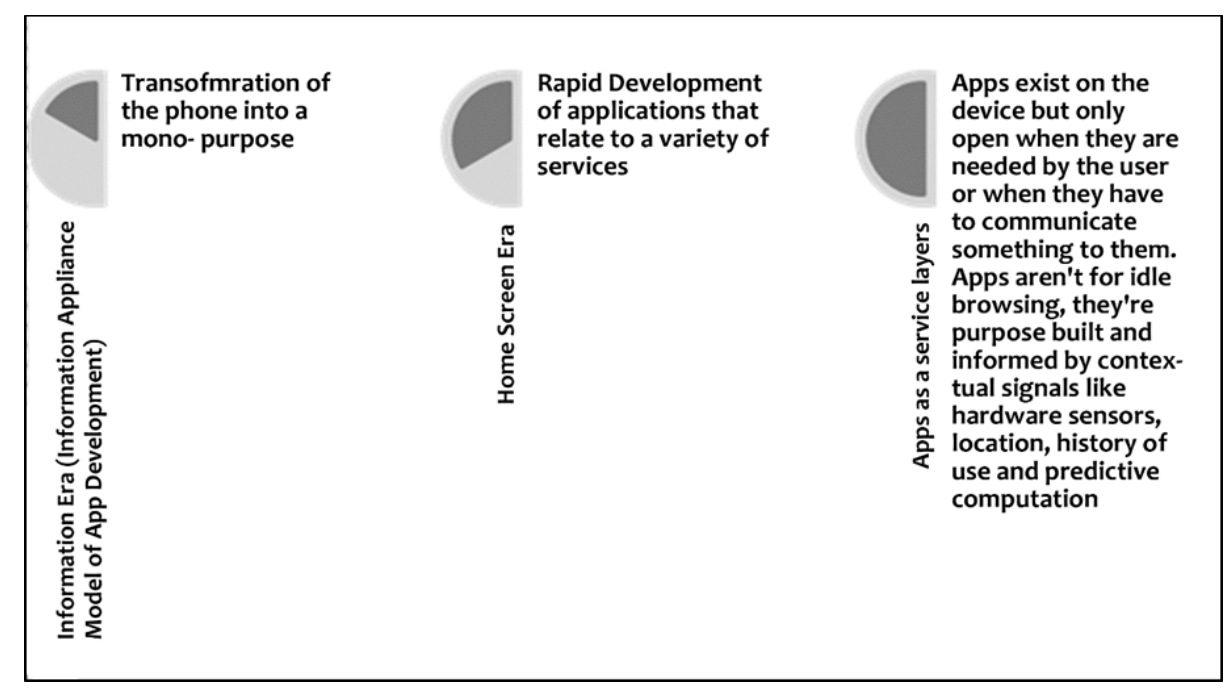

Figure 6. App development transformation phases in industry

\section{POPULAR BATTERY KILLERS AND THEIR ALTERNATIVES}

Amongst the most negative applications for a smartphone's battery are Google mobile services, who play a major role on battery drain running in the background of the device [36, 37], dynamic web components displayed in browsers [38], and location-aware applications running in the background [39]. The explanation that the latter is power-intensive is the use of the unavoidable GPS position detection process [40]. In addition, modern-day applications, which use emerging technology such as artificial intelligence, such as those that use fingerprint scanning or face recognition, are also amongst the battery-killers of the Android smartphone battery [41]. While not commonly discussed, one of the biggest battery killers is slow connection. This is illustrated in Wagner et al. report, where it is addressed that the energy costs per byte transmitted can be as many as six times higher if the relation is weak as opposed to when it is strong. This is especially noticeable in a communication-heavy application. The same study also demonstrates that the user habit of keeping Wi-fi or Bluetooth searching on has a similar battery-draining effect. Specifically, Wagner et al. illustrate: 'When $\mathrm{WiFi}$ is enabled, $50 \%$ (or $10 \%$ ) of users spend up to half (or 90\%) of their time with WiFi enabled but not connected.', highlighting the potential for energy savings. The frequency and duration of user interactions with their device for tasks such as checking the time or checking for notifications is another negative habit. $50 \%$ of users conduct this status check on average 9 times or more during the day, while 10 per cent check their computer on average 52 times a day.

\section{THE NEED TO SAVE SMARTPHONES BATTERY-LIFE DURING COVID-19 PANDEMIC}

With regards to the applications listed, there are some alternatives available, such as using energyefficient automatic location-triggered applications on smartphones. The use of proximity beacons is also an alternative in this context. Remote task execution is another way of reducing the workload of the smartphone and improving its battery life. In addition, due to the recognised issue with varying connectivity characteristics of application users, some applications have started releasing versions of their applications that spare the battery life through disabling the automatic processing of content or dynamic elements. An example of such application is Facebook Lite. In terms of habits, Android applications, such as a large-scale mobile battery recognition program called Carat, can help long-term users conserve more batteries, charge their smartphones less often, and learn how to control their batteries with less help from Carat overtime, as shown by Athukorala et al. study [42]. 
Finally, it is important to consider the need for battery saving in context of the recent COVID-19 pandemic. During a state of global lockdown, the use of smartphone devices has skyrocketed, and many governments have implemented location-tracking applications for their citizens as means of ensuring that the imposed governmental restrictions are being adhered to $[43,44]$. Since smartphones are battery-powered, the ability to save energy to ensure that the phone does not have to be charged too often or that it does not die and hinder location-tracking during this time of crisis is of crucial importance, affecting not only the efficiency of tracking, but also the usability of the smartphone device [45]. In the applications developed, both signal emission as well as reception costs energy. In addition, the precise patterns of signal emission and reception are regulated by the ND protocol, which aims to balance both discovery delay and energy expenditure. Such applications, as demonstrated previously, have a significant impact on the battery life, resulting in the development of battery saving applications, technologies and habits ever more necessary.

\section{CONCLUSION}

The literature has identified that smartphone user behaviour impacts energy consumption in the context of battery usage, as well as charging duration. While there are methods to reduce the battery's drain from mobile app use, they are not fully utilised by users. Simultaneously, the review has demonstrated the growing prevalence of mobile applications in daily lives, as well as the disproportionally (to battery life) increasing phone functionality, which results in the creation of a dependency towards smartphone use. Considering the identified trends of smartphone ownership growth globally (including in developing nations), growing integration of the digital dependency on individuals and increasing integration of the smartphones in lives of their owners, findings technical and behavioural solutions for improving the battery life is paramount.

Overall, it can be argued that the priority should be on designing more battery-saving strategies for Android devices in the mid to long term, as this is seen by academics as a possible way to reduce the impact mobile use has on the world. In the short-term, there is identified importance of developing informational mechanisms for guiding smartphone users' behaviour to; i) take advantage of the available battery saving settings, ii) develop habits and practices that spare the battery of their device, and iii) reduce the overcharging practices of their device's battery.

\section{ACKNOWLEDGEMENTS}

The authors graciously thank the College of Computer and Information Sciences, Prince Sultan University and the Faculty of Science and Technology, University Fernando Pessoa for their scientific and administrative support.

\section{REFERENCES}

[1] M. Kennedy, H. Venkataraman, and G. M. Muntean, "Energy consumption analysis and adaptive energy saving solutions for mobile device applications," in Green IT: Technologies and Applications. Springer, Berlin, Heidelberg, pp. 173-189, 2011.

[2] D. T. Wagner, A. Rice, and A. R. Beresford, "Device analyzer: understanding smartphone usage," in International Conference on Mobile and Ubiquitous Systems: Computing, Networking, and Services, 2013, pp. 195-208.

[3] S. K. Datta, C. Bonnet, and N. Nikaein, "Android power management: current and future trends," in 2012 The First IEEE Workshop on Enabling Technologies for Smartphone and Internet of Things (ETSIoT), Seoul, South Korea, 2012, pp. 48-53.

[4] D. Ferreira, A. K. Dey, and V. Kostakos, "Understanding human-smartphone concerns: a study of battery life," in International Conference on Pervasive Computing. Springer, Berlin, Heidelberg, pp. 19-33, 2011.

[5] A. Rahmati and L. Zhong, "Context-for-wireless: context-sensitive energy-efficient wireless data transfer," in Proceedings of the 5th international conference on Mobile systems, applications and services (MobiSys '07). Association for Computing Machinery, New York, NY, USA, 2007, pp. 165-178.

[6] K. N. Truong, J. A. Kientz, T. Sohn, A. Rosenzweig, A. Fonville, and T. Smith, "The design and evaluation of a task-centered battery interface," in Proceedings of the 12th ACM International Conference on Ubiquitous Computing. Association for Computing Machinery, Copenhagen, Denmark, 2010, pp. 341-350.

[7] L. Zhang, B. Tiwana, R. P. Dick, Z. Qian, Z. M. Mao, Z. Wang, and L. Yang, "Accurate online power estimation and automatic battery behavior based power model generation for smartphones," in 2010 IEEE/ACM/IFIP International Conference on Hardware/Software Codesign and System Synthesis (CODES+ISSS), Scottsdale, AZ, USA, Oct. 2010, pp. 105-114.

[8] Zidek, S. Tailor and R. Harle, "Bellrock: anonymous proximity beacons from personal devices," in 2018 IEEE International Conference on Pervasive Computing and Communications (PerCom), Athens, Greece, 2018, pp. $1-10$. 
[9] Saha, "Green computing," International Journal of Computer Trends and Technology (IJCTT), vol. 14, no. 2, pp. 46-50, 2014.

[10] S. D'Ambrosio, S. De Pasquale, G. Iannone, D. Malandrino, A. Negro, G. Patimo, A. Petta, V. Scarano, L. Serra, and R. Spinelli, "Mobile phone batteries draining: is green web browsing the solution?" in International Green Computing Conference, Dallas, TX, USA, 2014, pp. 1-10.

[11] M. Couto, T. Carção, J. Cunha, J. P. Fernandes, and J. Saraiva, "Detecting anomalous energy consumption in android applications," in Brazilian Symposium on Programming Languages, Springer, Cham, pp. 77-91, 2014.

[12] D. Bonino, L. De Russis, F. Corno, and G. Ferrero, "JEERP: energy-aware enterprise resource planning," IT Professional, vol. 16, no. 4, pp. 50-56, 2014.

[13] M. Sabharwal, A. Agrawal, and G. Metri, "Enabling green IT through energy-aware software," IT Professional, vol. 15, no. 1, pp. 19-27, 2013.

[14] K. Gai, M. Qiu, H. Zhao, L. Tao, and Z. Zong, "Dynamic energy-aware cloudlet-based mobile cloud computing model for green computing," Journal of Network and Computer Applications, vol. 59, pp. 46-54, 2016.

[15] H. Ba, W. Heinzelman, C. Janssen, and J. Shi, "Mobile computing-a green computing resource," in 2013 IEEE Wireless Communications and Networking Conference (WCNC), Shanghai, China, 2013, pp. 4451-4456.

[16] Sameh and A. Al-Masri, "Smartphone preventive customized power saving modes," International Journal of UbiComp, IJU, vol. 8, no. 1, pp. 1-15, 2017.

[17] W. C. Hu, "Sustainable ICTs and management systems for green computing," IGI Global, Hershey, PA, 2012.

[18] J. Sellwood and J. Crampton, "Sleeping android: exploit through dormant permission requests," in 3rd Annual ACM CCS Workshop on Security and Privacy in Smartphones and Mobile Devices (SPSM). Association for Computing Machinery, Berlin, Germany, 2013, pp. 55-66.

[19] Chris P., "Smartphone battery life over the years: a surprising study," Phone Arena, 2016. [Online]. Available: https://www.phonearena.com/news/Smartphone-battery-life-over-the-years-A-surprising-study_id82315.

[20] S. M. Bae, Y. H. Choi, S. M. Song, and S. E. Cha, "Effects of mother's smartphone dependency and maternal guilty feelings on early childhood emotion regulation," The Korean Journal of Community Living Science, vol. 28, no. 2, pp. 301-312, 2017.

[21] N. Park, Y. C. Kim, H. Y. Shon, and H. Shim, "Factors influencing smartphone use and dependency in South Korea," Computers in Human Behavior, vol. 29, no. 4, pp. 1763-1770, 2013.

[22] R. Triggs, "How far we've come: a look at smartphone performance over the past 7 years," Android Authority, 2015. [Online]. Available: https://www.androidauthority.com/smartphone-performance-improvements-timeline$626109 \%$.

[23] A. D. Ahad and M. Anshari, "Smartphone habits among youth: uses and gratification theory," International Journal of Cyber Behavior, Psychology and Learning (IJCBPL), vol. 7, no. 1, pp. 65-75, 2017.

[24] D. R. Méndez and F. Ortega-Mohedano, "The revolution in Millennial's usage habits and consumption of video in smartphones, the revealed crossroads," Revista Latina de Comunicación Social, vol. 72, pp. 704-718, 2017.

[25] Rosales and M. Fernández-Ardèvol, "Beyond WhatsApp: older people and smartphones," Romanian Journal of Communication and Public Relations, vol. 18, no. 1, pp. 27-47, 2016.

[26] J. Poushter, "Smartphone ownership and internet usage continues to climb in emerging economies," Pew Research Center, Washington, DC, 2016.

[27] P. Chandnani and R. Wadhvani, "Evolution of android and its impact on mobile application development," International Journal of Scientific Engineering and Technology, vol. 1, no. 3, pp. 80-85, 2012.

[28] G. Zichermann and C. Cunningham, "Gamification by design: implementing game mechanics in web and mobile apps," O'Reilly Media, Inc, London, 2011.

[29] D. Wang, Z. Xiang, and D. R. Fesenmaier, "Smartphone use in everyday life and travel," Journal of Travel Research, vol. 55, no. 1, pp. 52-63, 2016.

[30] J. Frizzo-Barker and P. A. Chow-White, "There's an App for That mediating mobile moms and connected careerists through smartphones and networked individualism," Feminist Media Studies, vol. 12, no. 4, pp. 580-589, 2012.

[31] L. G. Morrison, et al., "Understanding usage of a hybrid website and smartphone app for weight management: a mixed-methods study," Journal of Medical Internet Research, vol. 16, no. 10, p. e201, 2014.

[32] H. E. Payne, C. Lister, J. H. West, and J. M. Bernhardt, "Behavioral functionality of mobile apps in health interventions: a systematic review of the literature," JMIR mHealth and uHealth, vol. 3, no. 1, p. e20, 2015.

[33] J. Cho, "Roles of smartphone app use in improving social capital and reducing social isolation," Cyberpsychology, Behavior, and Social Networking, vol. 18, no. 6, pp. 350-355, 2015.

[34] C. A. Hoffner and S. Lee, "Mobile phone use, emotion regulation, and well-being," Cyberpsychology, Behavior, and Social Networking, vol. 18, no. 7, pp. 411-416, 2015.

[35] J. D. Elhai, J. C. Levine, R. D. Dvorak, and B. J. Hall, "Non-social features of smartphone use are most related to depression, anxiety and problematic smartphone use," Computers in Human Behavior, vol. 69, pp. 75-82, 2017.

[36] M. Martins, J. Cappos, and R. Fonseca, "Selectively taming background android apps to improve battery lifetime," in 2015 \{USENIX\} Annual Technical Conference (\{USENIX\}\{ATC\} 15). USENIX Association, Santa Clara, CA, 2015, pp. 563-575.

[37] M. Panzarino, "Foursquare's swarm and the rise of the invisible app," Tech Crunch, 2014. [Online]. Available: https://techcrunch.com/2014/05/15/foursquares-swarm-and-the-rise-of-the-invisible-app/?guccounter=1.

[38] D. H. Ting, S. F. Lim, T. S. Patanmacia, C. G. Low and G. C. Ker, "Dependency on smartphone and the impact on purchase behaviour," Young Consumers, vol. 12, no. 3, pp. 193-203, 2011. 
[39] Y. Liu, C. Xu, and S. C. Cheung, "Where has my battery gone? Finding sensor related energy black holes in smartphone applications," in 2013 IEEE International Conference on Pervasive Computing and Communications (PerCom), San Diego, CA, USA, 2013, pp. 2-10.

[40] Y. Man and E. C. H. Ngai, "Energy-efficient automatic location-triggered applications on smartphones," Computer Communications, vol. 50, pp. 29-40, 2014.

[41] E. Cuervo, A. Balasubramanian, D. Cho, A. Wolman, S. Saroiu, R. Chandra, and P. Bahl, "MAUI: making smartphones last longer with code offload," in Proceedings of the 8th international conference on Mobile systems, applications, and services (MobiSys '10), Association for Computing Machinery, NY, USA, 2010, pp. 49-62.

[42] K. Athukorala, E. Lagerspetz, M. von Kügelgen, A. Jylhä, A. J. Oliner, S. Tarkoma, and G. Jacucci, "How carat affects user behavior: implications for mobile battery awareness applications," in Proceedings of the SIGCHI Conference on Human Factors in Computing Systems, Association for Computing Machinery, Toronto, Ontario, Canada, 2014, pp. 1029-1038.

[43] R. Kitchin, "Civil liberties or public health, or civil liberties and public health? Using surveillance technologies to tackle the spread of COVID-19," Space and Polity, 2020, pp. 1-20.

[44] J. Stanley and J. S. Granick, "The limits of location tracking in an epidemic," American Civil Liberties Union, 2020.

[45] P. H. Kindt, T. Chakraborty, and S. Chakraborty, "How reliable is smartphone-based electronic contact tracing for COVID-19?" arXiv preprint arXiv:2005.05625, 2020.

\section{BIOGRAPHIES OF AUTHORS}

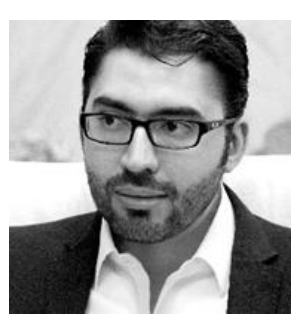

Abdullah Mahmoud Almasri holds a bachelor of science degree in Information Systems and a Master of Science degree in Software Engineering from Prince Sultan University, Saudi Arabia. Senior Lecturer and researcher of Computer Science and Information Systems at Prince Sultan University since 2015. His current research interests include Mobile Computing, Power-Aware Applications, and Systems Design.

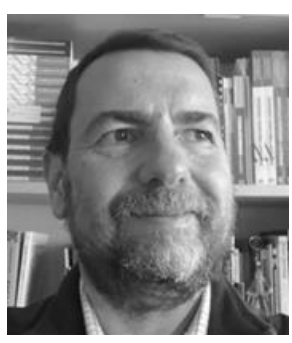

Luis Borges Gouveia holds a Habilitation in Engineering and Industrial Management from the University of Aveiro, Portugal, and a Ph.D. in Computer Science from the University of Lancaster, UK. Full Professor at University Fernando Pessoa, Porto, Portugal where is the coordinator of the Ph.D. program in Information Science. His main interests are related to how computers and digital applications can impact people, and include novel application to provide better sustainable technology usage. 